\title{
Physicians' Attitude towards The Use of Social Media for Professional Purposes in Saudi Arabia
}

\author{
Turki Alanzi (D) and Susan Al-Yami \\ Health Information Management and Technology Department, College of Public Health, Imam Abdulrahman Bin Faisal University, \\ Dammam, Saudi Arabia \\ Correspondence should be addressed to Turki Alanzi; talanzi@iau.edu.sa
}

Received 2 April 2019; Accepted 9 September 2019; Published 2 December 2019

Academic Editor: Manolis Tsiknakis

Copyright (c) 2019 Turki Alanzi and Susan Al-Yami. This is an open access article distributed under the Creative Commons Attribution License, which permits unrestricted use, distribution, and reproduction in any medium, provided the original work is properly cited.

\begin{abstract}
Purpose. In relation to this research, only a few studies have been carried out around the world. However, in Saudi Arabia, there have been no investigations into this subject. In this sense, the objective of this study was to investigate the physicians' attitudes towards the use of social media for professional purposes in Saudi Arabia. Methods. A cross-sectional study was conducted among 235 physicians from different regions of Saudi Arabia. The data were collected by means of a survey. The survey questionnaire was distributed using the WhatsApp application. Descriptive statistics were used to analyze the results. Results. The most common social media used by the respondents was Facebook, and the majority of the participants agreed that social media improved their knowledge and skills. However, most of the participants did not interact with patients using these tools, did not feel comfortable conducting an online consultation, and believed that social media affected the choice of the healthcare provider. Similarly, $30.6 \%$ of the respondents opined that it is not appropriate to search online information about patients, and $44.3 \%$ of them considered that patients would not trust the medical advice if a physician obtained the information from a website. Conclusion. The results showed that the majority of the respondents considered that social media improved the knowledge and abilities of physicians. In addition, the respondents reflected that there were ethical issues that must be taken into account when using social media and more than half of them did not interact with their patients employing these tools. The outcomes of this research will help to develop programs directed at the physicians in Saudi Arabia to enhance their knowledge, professional skills, medicine practice, patient-doctor interaction, and handle the risks involved in the use of social media.
\end{abstract}

\section{Introduction}

The use of social media in almost all human activities is growing every day and has reached unprecedented statistics worldwide. In this regard, for example, the number of users of Facebook, YouTube, WhatsApp, Facebook Messenger, Instagram, Twitter, Skype, and Snapchat by April 2018 were $2234,1500,1300,813,330,300$, and 255 million people, respectively [1].

This increasing use of social media as a platform for universal communication has also reached the field of healthcare and has become a tool that doctors and other health professionals use to participate, share opinions, photos, audios, videos, and collect beneficial information to improve their professional knowledge and provide care to their patients [2-6]. Also, the use of social messaging applications and telemedicine websites has allowed patients to increase knowledge and education about their diseases, share their experience, and receive medical treatment, without the need for face-to-face appointments with their doctors [7-11]. In general, these social networking sites offer a variety of features that serve for different purposes according to the needs of users and can include blogs, social networks, video and photo exchange sites, wikis, and other dissemination alternatives. In relation to these general topics, several authors have studied the utilization of social media by doctors, students, and patients, emphasizing their uses, benefits, risks, barriers, and ethical and legal aspects $[4,12-15]$.

On the other hand, considering the objectives of our research, some studies have analyzed the opinions and attitudes of doctors on the use of social media in different fields of medicine $[2-5,15-19]$. In the same way, in previous studies, 
the use of social media platforms has been considered as efficient instruments for education, exchange of ideas, and communication of experiences among physicians $[3,20,21]$. Additionally, some authors have analyzed the benefits, risks, potential challenges, and ethical and legal dilemmas that imply the management of these tools for doctors, nurses, and other healthcare professionals $[3-5,15,17,18,22]$.

In another context, it should be noted that in the literature there are models that allow evaluating the attitude of people towards the use of specific technologies. One of these models is the technology acceptance model (TAM), which according to some recent versions considers that the attitude of people towards the use of a certain technology depends on the ease of use, availability, benefits, risks, and other factors [23]. This model has been used in some studies related to the use of social media and could be adapted to the subject of our research [23-26].

As we have seen, in different countries of the world, a few investigations have been conducted on the attitudes and opinions of physicians about the use of social media in the healthcare field; however, in Saudi Arabia, to the knowledge of the author, no research has been carried out on this topic, despite the massive use of social media in this region, where the penetration percentages of WhatsApp use, YouTube, Facebook, Instagram, and Twitter by 2017 have reached figures of $73 \%, 71 \%, 66 \%, 54 \%$, and $52 \%$, respectively [27].

In this sense, the objective of this research was to describe the physicians' attitude towards the use of social media for professional purposes in Saudi Arabia. The outcomes of this research will permit to develop programs directed to enhance knowledge, professional skills, medical practice, and patient-doctor interaction among physicians in the Kingdom of Saudi Arabia.

\section{Methods}

2.1. Study Settings and Participants. In order to assess the attitude of physicians towards the use of social media for professional purposes in Saudi Arabia, which is the object of this research, a cross-sectional study was carried out among physicians who practice in different regions of this country. Subjects were selected through the convenient nonprobability sampling method, and data were collected by means of a survey designed for such a purpose [28]. The population selected in this research consisted of 300 physician users of social media who were members of different WhatsApp groups in Saudi Arabia. This population was easily accessible, had experience in social media practices, and could provide adequate information on the research questions. All this population was contacted and the survey questionnaire was sent to them. Of this population, 235 participants filled out and returned the questionnaire. In other words, the response rate was $78.33 \%$.

2.2. Description of the Questionnaire. The survey questionnaire contained 16 questions and it was designed using the Google forms provided in this link [29]. The survey questionnaire for this research was created based on surveys published in the literature and the experience of the researchers involved in this work [30]. To validate the study instrument, the questionnaire was sent to a small group of doctors who were users of social media in order to see if the questions were well-formulated and allowed to obtain the answers to the research questions. They filled out and returned the questionnaire through WhatsApp.

From the questions posed in the first part of the questionnaire (5 questions), the demographic information of the participants was obtained (age, gender, region, experience, and work position). Then, from the second part of the questionnaire consisting of the following 5 questions it is possible to know the types of social media used by the respondents, and how they employed these media for the medical treatment of their patients: which social media do you use at least once a week?; how many hours do you use social media per day?; as a physician do you interact with patients via email or social media?; which type of online media does your workplace currently have for the patient to access?; and do you ever discuss internet or social media usage with your patients?. Finally, from the 6 questions of the third part of the questionnaire, we got the opinions of the participants about the use of social media in various topics of their professional career: do you think social media can help to improve your knowledge and skills in your career?; do physicians have a duty to rebut inappropriate or inaccurate health information posted online?; if a physician obtained the medical information from a related mobile phone application or website, would a patient trust medical advice?; is it appropriate for physicians to look up any available online information about a patient as part of regular clinical practice?; would you be comfortable conducting a consultation with a patient via skype or other online telecommunications?; and would social media affect the patients choice of the healthcare provider?

It is pertinent to clarify that in the above questions we can detect the independent and dependent variables of our research knowing that the dependent variables respond to the independent variable. In other words, the independent variables are associated with the cause and the dependent ones to the effect. In our case, the dependent variables are the responses of the participants expressed in percentages. As an example, in the question; Do you think that social media can help to improve your knowledge and skills in your area? The independent variable is "social media", and the dependent variable is "knowledge and skills", and so on with the rest of the questions.

2.3. Data Collection. The data required for evaluating the physicians' attitude towards the use of social media in Saudi Arabia were collected using a survey. The survey questionnaire was distributed to 300 physicians of different categories from interns to consultants who practice in this region using the WhatsApp application. From this sample, we received responses from 235 physicians.

2.4. Statistical Analysis. Descriptive statistics in terms of frequency and percentage were used to analyze the results of this study. Also, the significance between the demographic variables and the attitude of physicians was tested by means of the Chi-square test. The analysis was done using the SPSS 21.0 version and $p$-values less than 0.05 were considered as significant. 
TABLE 1: Demographic data of the respondents $(n=235)$.

\begin{tabular}{|c|c|c|}
\hline Variables & $n$ & $\%$ \\
\hline \multicolumn{3}{|l|}{ Age in years } \\
\hline Less than 25 & 25 & 10.6 \\
\hline $25-35$ & 103 & 43.8 \\
\hline $36-45$ & 38 & 16.2 \\
\hline $46-55$ & 46 & 19.6 \\
\hline 56-65 & 23 & 9.8 \\
\hline \multicolumn{3}{|l|}{ Gender } \\
\hline Male & 64 & 27.2 \\
\hline Female & 171 & 72.3 \\
\hline \multicolumn{3}{|l|}{ Region } \\
\hline Center & 45 & 19.1 \\
\hline East & 165 & 70.2 \\
\hline North & 2 & 0.8 \\
\hline South & 12 & 5.1 \\
\hline West & 11 & 4.8 \\
\hline \multicolumn{3}{|c|}{ Experience in years } \\
\hline $0-2$ & 77 & 32.7 \\
\hline $3-5$ & 24 & 10.2 \\
\hline $6-10$ & 31 & 13.2 \\
\hline More than 10 & 102 & 43.4 \\
\hline \multicolumn{3}{|l|}{ Position } \\
\hline Consultant & 80 & 34.0 \\
\hline Resident & 79 & 33.6 \\
\hline Specialist & 38 & 16.2 \\
\hline Interns & 29 & 12.3 \\
\hline Others & 9 & 3.8 \\
\hline
\end{tabular}

\section{Results}

The demographic data of the 235 respondents are shown in Table 1. According to this table, most of the participants $(72.3 \%)$ were female, more than half of the respondents (54.4\%) were less than 35 years old, and the majority of them (70.2\%) belonged to the eastern region of Saudi Arabia. Also, $34.0 \%$ of the respondents were consultant and $33.6 \%$ were resident. Similarly, $56.1 \%$ of the surveyed physicians have less than 10 years of experience.

Table 2 presents the questions and responses of the participants about the use of social media. In a descending order, the respondents used the following platforms: Facebook (37.9\%), YouTube (35.7\%), Twitter (34.5\%), Google+ (17.9\%), Research gate (9.8\%), LinkedIn (7.7\%), and Instagram (5.9\%). Also, $46.4 \%$ of the workplaces utilized text message for patients' access, and almost half of the participants (45.5\%) spent 2 to 3 hours per day working on social media platforms. Most of the surveyed physicians (67.3\%) did not interact with patients via e-mail or social media. In addition, more than half of the participants (57.5\%) did not discuss internet or social media usage with patients.

The questions and the participants' opinions about the use of social media are described in Table 3. This table shows that $76 \%$ of respondents agreed that social media enable them to improve their knowledge and skills, and $70 \%$ of them thought that physicians have a duty to rebut inappropriate or
TABLE 2: Questions and responses about the type and ways of using social media $(n=235)$.

\begin{tabular}{|c|c|c|}
\hline Questions & $n$ & $\%$ \\
\hline \multicolumn{3}{|c|}{ Which social media do you use at least once a week? } \\
\hline Facebook & 89 & 37.9 \\
\hline YouTube & 84 & 35.7 \\
\hline Twitter & 81 & 34.5 \\
\hline Google+ & 42 & 17.9 \\
\hline Research gate & 23 & 9.8 \\
\hline LinkedIn & 18 & 7.7 \\
\hline Instagram & 14 & 5.9 \\
\hline \multicolumn{3}{|c|}{ How many hours do you use social media per day? } \\
\hline Never & 3 & 1.3 \\
\hline $0-1$ & 69 & 29.4 \\
\hline $2-3$ & 107 & 45.5 \\
\hline $4-6$ & 36 & 15.6 \\
\hline More than 6 & 20 & 8.5 \\
\hline \multicolumn{3}{|c|}{ As a physician do you interact with patients via email or social media? } \\
\hline Yes & 77 & 32.7 \\
\hline No & 158 & 67.3 \\
\hline \multicolumn{3}{|c|}{$\begin{array}{l}\text { Which type of online media does your work place currently have for } \\
\text { patient to access? }\end{array}$} \\
\hline Website & 52 & 22.1 \\
\hline Text message & 109 & 46.4 \\
\hline Instagram & 5 & 2.1 \\
\hline Facebook & 12 & 5.1 \\
\hline Others & 49 & 24.3 \\
\hline \multicolumn{3}{|c|}{ Do you ever discuss internet or social media usage with your patients? } \\
\hline Yes & 100 & 42.5 \\
\hline No & 135 & 57.5 \\
\hline
\end{tabular}

inaccurate health information posted online. Similarly, $30.6 \%$ of respondents disagreed that it is appropriate for physicians to look up any available online information about a patient as part of regular clinical practice, and $44.3 \%$ of participants disagreed that a patient would trust the medical advice if a physician obtained the medical information from a related social media website. On the other hand, more than half of surveyed, $53 \%$, did not feel comfortable conducting a consultation with a patient using online telecommunications. In addition, most of the respondents $(74.0 \%)$ stated that social media will affect the patients choice of the healthcare provider.

Table 4, applying the Chi-square test shows the statistical importance of the respondent's age and the type of social networks used. Similarly, the statistical significance between the demographic variables of the respondents and the role of social media to improve knowledge and skills is presented in Table 5 using the probability value found by the Chi-square test.

\section{Discussion}

The findings of this study about the physicians' attitudes towards the use of different types of social media in Saudi Arabia indicated that the most used social media platforms by the participants were in decreasing order: Facebook (37.9\%), YouTube (35.7\%), Twitter (34.5\%), Google+ (17.9\%), 
TABle 3: Questions and opinions about the use of social media $(n=235)$.

\begin{tabular}{lc}
\hline Questions & $\%$ \\
\hline Do you think social media can help to improve your knowledge and \\
skills in your career? \\
Yes & 76 \\
No & 12 \\
Unsure & 12 \\
\hline Do physicians have a duty to rebutt inappropriate or inaccurate \\
health information posted online? \\
Yes \\
No & 70 \\
Unsure & 12 \\
Is it appropriate for physicians to look up any available online & 18 \\
information about a patient as part of regular clinical practice? & 33.2 \\
Agree & 36.2 \\
Neutral & 30.6 \\
Disagree & 74 \\
\hline If a physician obtained the medical information from a related mobile \\
phone application or website, would a patient trust medical advice? \\
Agree & 18.7 \\
Neutral & 37 \\
Disagree & 44.3 \\
\hline Would you be comfortable conducting a consultation with a patient \\
via skype or other online telecommunications? \\
Yes & 24 \\
No & 53 \\
Unsure & 23 \\
\hline Would social media affect the patients choice of healthcare provider? & \\
Agree & \\
Neutral & \\
Disagree & \\
\hline &
\end{tabular}

Research gate (9.8\%), LinkedIn (7.7\%), and Instagram (3.9\%). In addition, $90.5 \%$ of participants utilized these social media tools between 1 and 3 hours a day. In this regard, in a survey carried out with participants from 29 countries it was found that more than half of the participants considered that Facebook was more useful than Twitter for professional purposes; this finding coincides with the general tendency observed in our research [31]. Similarly, Facebook was reported as the most used social media platform $(59.9 \%)$ by Australian doctors [30].

In our study, we detected that $76 \%$ of the participants believed that social media contributes to improving the knowledge and skills of the participants. About this topic, previous studies have suggested the utility of social media as an educational tool for medical professionals [3, 20,21].

Our results also showed that more than half of the participants $(67.3 \%)$ did not interact with patients using social media, and $57.5 \%$ of the participants did not discuss with patients the social media or the Internet usage. In relation to this matter, similar results have been observed in other investigation in which more than half of the respondents (59\%) were opposed to employing social media for patient interaction [32].
TABLE 4: Statistical significance between the respondents' age and the type of social media usage (Chi-square test).

\begin{tabular}{|c|c|c|c|c|c|c|}
\hline \multirow{2}{*}{$\begin{array}{l}\text { Type of } \\
\text { social } \\
\text { media }\end{array}$} & \multicolumn{5}{|c|}{ Age group in years } & \multirow{2}{*}{$\begin{array}{c}P \\
\text { value }\end{array}$} \\
\hline & $\begin{array}{c}\text { Less } \\
\text { than } 25\end{array}$ & $25-35$ & $36-45$ & $46-55$ & $56-65$ & \\
\hline Facebook & 23 & 56 & 6 & 3 & 1 & \multirow{7}{*}{0.021} \\
\hline Twitter & 13 & 20 & 34 & 12 & 2 & \\
\hline Google+ & 15 & 20 & 4 & 2 & 1 & \\
\hline LinkedIn & 3 & 6 & 2 & 6 & 1 & \\
\hline YouTube & 10 & 17 & 19 & 21 & 17 & \\
\hline Instagram & 6 & 2 & 0 & 2 & 4 & \\
\hline $\begin{array}{l}\text { Research } \\
\text { gate }\end{array}$ & 2 & 3 & 6 & 2 & 10 & \\
\hline
\end{tabular}

TABLE 5: Statistical significance between the demographic variables of the respondents and the role of social media to improve knowledge and skills in career (Chi-square test).

\begin{tabular}{lcc}
\hline Variables & Yes (\%) & $P$ value \\
\hline Age & 25 & \\
Less than 25 & 103 & \\
$25-35$ & 38 & $<0.001$ \\
$36-45$ & 46 & \\
$46-55$ & 23 & \\
$56-65$ & & \\
\hline Gender & 64 & \\
Male & 171 & \\
Female & & \\
Experience in years & 77 & \\
$0-2$ & 22 & \\
3-5 & 34 & \\
6-10 & 102 & \\
More than 10 & & \\
Position & 80 & \\
Consultant & 61 & \\
Resident & 39 & \\
Specialist & 19 & \\
GP & 29 & \\
Interns & 7 & \\
Others & & \\
\hline
\end{tabular}

About the information published online, we observed that $70 \%$ of the respondents considered that the doctors have the duty to refute any inappropriate information published on social networks. Alike, $30.6 \%$ of respondents thought that it is not appropriate for physicians to look up any patient information available online; however, $33.2 \%$ of respondents had an opposite opinion to this concern; and $36.2 \%$ had a neutral attitude on this matter; regarding this topic, several authors have considered the importance of maintaining the confidentiality of patients [12-15, 33, 34].

Additionally, we appreciated that $44.3 \%$ of the participants believed that a patient would not trust the advice of a doctor if he takes medical information from social media; regarding this issue, $18.7 \%$ presented an opposing opinion to this 
concern, and $37 \%$ had an impartial judgment. As well, more than half of the respondents (53\%) did not feel comfortable conducting a consultation with a patient online; a similar response is observed in another research in which $60.8 \%$ of respondents did not feel comfortable interacting online with their patients [30]. Besides, the majority of respondents (74\%) opined that social media affects the selection of the healthcare provider.

On the other hand, it is possible to infer that there was an association between age and the type of social media used since the $\mathrm{p}$-values calculated using the Chi-square test were less than 0.05 . According to this information, we appreciated that most of the young people (25-35 years old) used Facebook, preferably; and, the older ones (56-65 years old) mostly utilized Research gate.

Correspondingly, the calculated p-value employing the Chi-square test suggested that there was a statistically significant relationship between the age of the respondents and the role of social media to improve knowledge and skills in the professional career. In this sense, in contrast to most of the young participants, the older respondents felt that social media information did not contribute significantly to improve knowledge and professional skills. Additionally, no significant statistical relationship was observed between the gender, experience, position, and the impact of social media to improve knowledge and professional skills.

It is pertinent to point out that the main limitation of this work was the small sample size of participants in comparison with the number of doctors in Saudi Arabia which limits its general validity. Also, since the convenient non probability sampling method was used in this study, the results found are only valid for the sample of the 235 respondents of social media users belonging to the different WhatsApp groups in Saudi Arabia who answered and filled out the questionnaire of the survey. The results cannot be generalized to the total population of doctors in Saudi Arabia. In this regard, to obtain information that allows generalizing the results to the entire population, it is necessary to increase the sample size since the total population of doctors living in Saudi Arabia was about 10,000 in 2018 [35]. Therefore, for future studies, a larger sample size is recommended with a cluster sampling that includes the different geographical regions of Saudi Arabia. Also, it is convenient to conduct studies to examine the differences of opinion among physicians and other categories of health professionals about the use of social networks to share and exchange medical knowledge. Likewise, it would be convenient to conduct an investigation into the differences in the uses of social media among doctors in Saudi Arabia and other places in the world. Similarly, it would be interesting to investigate whether there are cultural, technical, or practical reasons that limit the use of social media for the professional training and education of doctors in this country. Additionally, it would be useful to carry out a qualitative analysis about the thinking of physicians and to contextualize this study within a theoretical framework such as the TAM model that could help to explain the attitudes of physicians towards the use of social media for professional purposes in Saudi Arabia.

\section{Conclusion}

The results of this research showed that the most used social by the surveyed physicians was Facebook and the majority of respondents believed that social media offer and disseminate scientific and technological information through articles, books, forums, case studies, videos, and other systems that contribute to improving the knowledge and development of the professional skills of doctors.

However, most of the respondents did not interact with patients and thought that there were ethical dilemmas related to the privacy of patients and the publication of inappropriate information that should be taken into account in the use of social media. Finally, the outcomes of this investigation will allow creating programs focused to improve knowledge, professional skills, medicine practice, patient-doctor interaction, and handle the risks involved in the use of social media among physicians in the Kingdom of Saudi Arabia.

\section{Data Availability}

The data used to support the findings of this study are available from the corresponding upon request.

\section{Conflicts of Interest}

The authors declare that they have no conflicts of interest.

\section{References}

[1] Most famous social network sites worldwide as of April 2018, ranked by number of active users (in millions), 2018, https:// www.statista.com/statistics/272014/global-social-networksranked-by-number-of-users/.

[2] W. Chan and A. Leung, "Use of social network sites for communication among health professionals: systematic review," Journal of Medical Internet Research, vol. 20, no. 3, p. e117, 2018.

[3] K. Fehring, I. De Martino, A. S. McLawhorn, and P. K. Sculco, "Social media: physicians-to-physicians education and communication," Current Reviews in Musculoskeletal Medicine, vol. 10, no. 2, pp. 275-277, 2017.

[4] K. Bennett and C. Vercler, "When is posting about patients on social media unethical "Medutainment"?, AMA Journal of Ethics, vol. 20, no. 4, pp. 328-335, 2018.

[5] R. Yousuf, S. Bakar, M. Haque, M. N. Islam, and A. Salam, "Medical professional and usage of social," Bangladesh Journal of Medical Science, vol. 16, no. 4, p. 609, 2017.

[6] Z. Surani, R. Hirani, A. Elias et al., "Social media usage among health care providers," BMC Research Notes, vol. 10, no. 1, 2017.

[7] M. Househ, "The use of social media in healthcare: organizational, clinical, and patient perspectives," Studies in Health Technology and Informatics, vol. 183, pp. 244-248, 2013.

[8] K. Volppk and N. Mohta, "Patient engagement survey: social networks to improve patient health," NEJM Catalyst Insights Report, 2018.

[9] K. Thompson, "The use of social media in diabetes education," DNP Scholarly Project East Carolina University, 2017. 
[10] E. Gabarron, M. Bradway, and E. Arsand, "What are diabetes patients discussing on social media?," International Journal of Integrated Care, vol. 16, no. 5, p. 14, 2016.

[11] E. Shaffer-Hudkins, N. Johnson, and S. Melton, "Social media use among Individuals with diabetes," The International Journal of Communication and Health, p. 4, 2014.

[12] L. Campbell, Y. Evans, M. Pumper, and M. A. Moreno, "Social media use by physicians: a qualitative study of the new frontier of medicine," BMC Medical Informatics and Decision Making, vol. 16, no. 1, 2016.

[13] S. Moorhead, D. Hazlett, L. Harrison, J. K. Carroll, A. Irwin, and C. Hoving, "A new dimension of health care: systematic review of the uses, benefits, and limitations of social media for health communication," Journal of Medical Internet Research, vol. 15, no. 4, p. e85, 2013.

[14] K. Chretien and T. Kind, "Social media and clinical care: ethical, professional, and social implications," Circulation, vol. 127, no. 13, pp. 1413-21, 2013.

[15] C. L. Ventola, "Social media and health care professionals: benefits, risks, and best practices," Pharmacy and Therapeutics, vol. 39, no. 7, pp. 491-520, 2014.

[16] P. Karnabi and R. Deonandan, "Attitudes regarding physicians' use of social media," Journal of Epidemiology and Community Health, vol. 69, no. 1, pp. A2.1-A2, 2015.

[17] B. S. McGowan, M. Wasko, B. S. Vartabedian, R. S. Miller, D. D. Freiherr, and M. Abdolrasulnia, "Understanding the factors that influence the adoption and meaningful use of social media by physicians to share medical information," Journal of Medical Internet Research, vol. 14, no. 5, p. e117, 2012.

[18] B. E. Ibarra-Yruegas, C. R. Camara-Lemarroy, L. Loredo-Díaz, and O. Kawas-Valle, "Social networks in medical practice," Medicina Universitaria, vol. 17, no. 67, pp. 108-113, 2015.

[19] B. Zucker and C. Kontovounisios, "It is time to improve the quality of medical information distributed to students across social media," Advances in Medical Education and Practice, vol. 9, pp. 203-205, 2018.

[20] R. S. Gonzalez, S. M. Amer, N. B. Yahia et al., "Facebook discussion groups provide a robust worldwide platform for free pathology education," Archives of Pathology \& Laboratory Medicine, vol. 141, no. 5, pp. 690-695, 2016.

[21] C. C. Cheston, T. E. Flickinger, and M. S. Chilsolm, "Social media use in medical education: a systematic review," Academic Medicine, vol. 88, no. 6, pp. 893-901, 2013.

[22] E. Nikiphorou and F. Berenbaum, "Patient-physician interaction on social media: the physician's point of view," EMJ Innovations, vol. 2, no. 1, pp. 40-42, 2018.

[23] V. Ramadani, A. Demiri, and S. Demiri, "Social media channels: the factors that influence the behavioural intention of customers," International Journal of Business and Globalisation, vol. 12, no. 3, p. 297, 2014.

[24] W. Al-Rahimi, M. Othman, and M. Musa, "Using TAM model to measure the use of social media for collaborative learning," International Journal of Engineering Trends and Technology, vol. 5, no. 2, 2013.

[25] R. Rauniar, G. Rawski, J. Yang, and B. Johnson, “Technology acceptance model (TAM) and social media usage: an empirical study on Facebook," Journal of Enterprise Information Management, vol. 27, no. 1, pp. 6-30, 2014.
[26] B. Wirtz and V. Gottel, "Technology acceptance in social media review, synthesis and directions for future empirical research," Journal of Electronic Commerce Research, vol. 17, no. 2, 2016.

[27] Penetration of leading social networks in Saudi Arabia as of 3rd quarter 2017, 2018, https://www.statista.com/statistics/284451/ saudi-arabia-social-network-penetration/.

[28] M. Setia, "Methodology series module 5: sampling strategies," Indian Journal of Dermatology, vol. 61, no. 5, pp. 505-509, 2016.

[29] Survey Questionnaire, 2018, https://docs.google.com/forms/d/ e/1FAIpQLSf5KQBKApeWG7IqB3DzWQ3YPiLwJ9kS29Ms0H $\mathrm{dOVnUXUqF} 4 \mathrm{Xw} /$ viewform? $\mathrm{c}=0 \& \mathrm{w}=1$.

[30] J. Brown, C. Ryan, and A. Harris, "How doctors view and use social media: a national survey," Journal of Medical Internet Research, vol. 16, no. 12, p. e267, 2014.

[31] E. Carlquist, N. Lee, S. Shalin, M. Goodman, and J. M. Gardner, "Dermatopathology and social media," Archives of Pathology \& Laboratory Medicine, vol. 142, no. 2, pp. 184-190, 2018.

[32] K. Jain, M. B. Fuoco, G. Fervaha, and M. J. Leveridge, "A new wave of urologists? Graduating urology residents' practices of and attitudes toward social media," Canadian Urological Association Journal, vol. 12, no. 7, pp. E298-313, 2018.

[33] A. Bowser, "Social media behavior and attitudes of us physicians: implications for continuing education providers," 2017, https:// www.clinicaloptions.com/-/media/publications/2016/11_2016_ social_media_white_paper/white_paper_social_media. pdf?rev=30f2e6480e044ffd985d50f9ab43e2f5.

[34] S. Panahi, J. Watson, and H. Partridge, "Social media and physicians: exploring the benefits and challenges," Health Informatics Journal, vol. 22, no. 2, pp. 99-112, 2016.

[35] Number of physicians working in Saudi Arabia from to 2018 by nationality, 2019, https://www.statista.com/statistics/629028/ saudi-arabia-number-of-physicians-by-nationality/. 


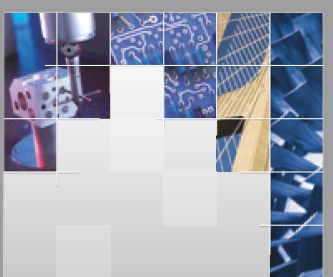

\section{Enfincering}
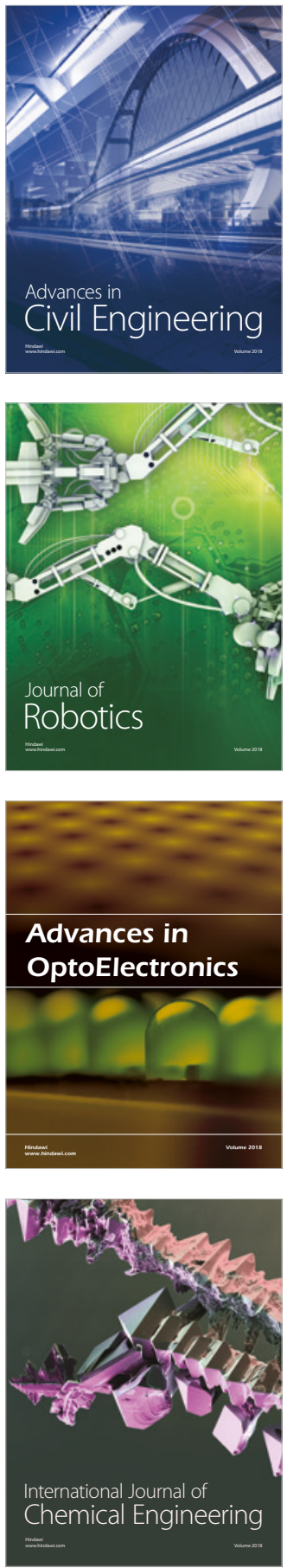

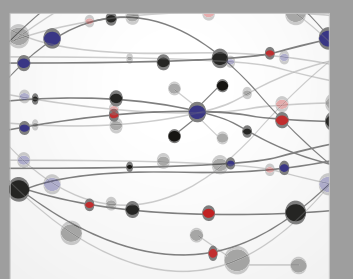

\section{Rotating \\ Machinery}

The Scientific World Journal

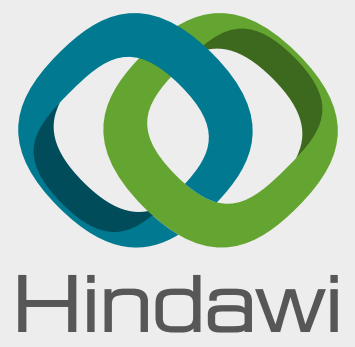

Submit your manuscripts at

www.hindawi.com
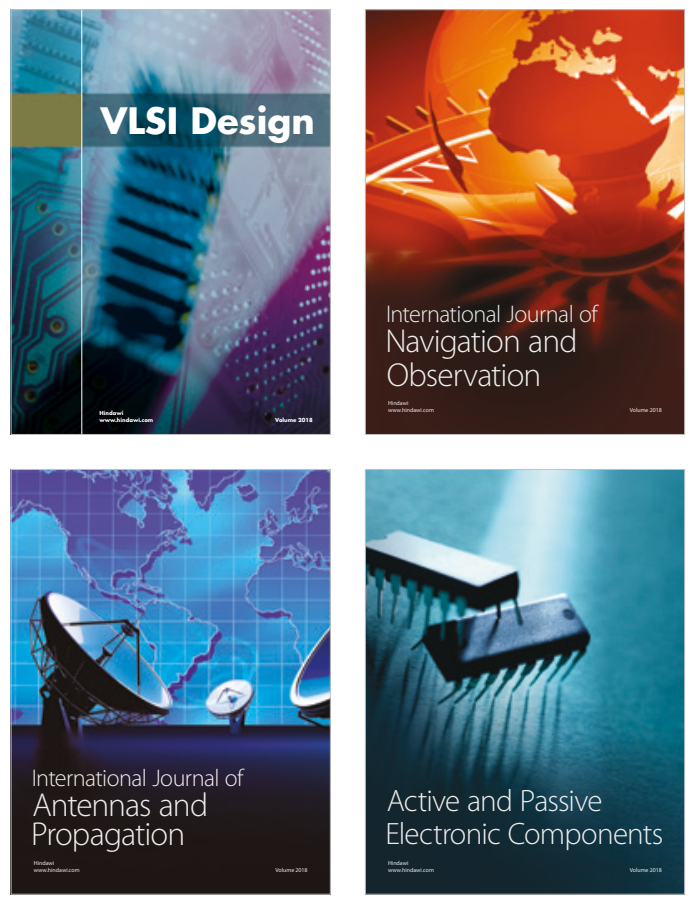
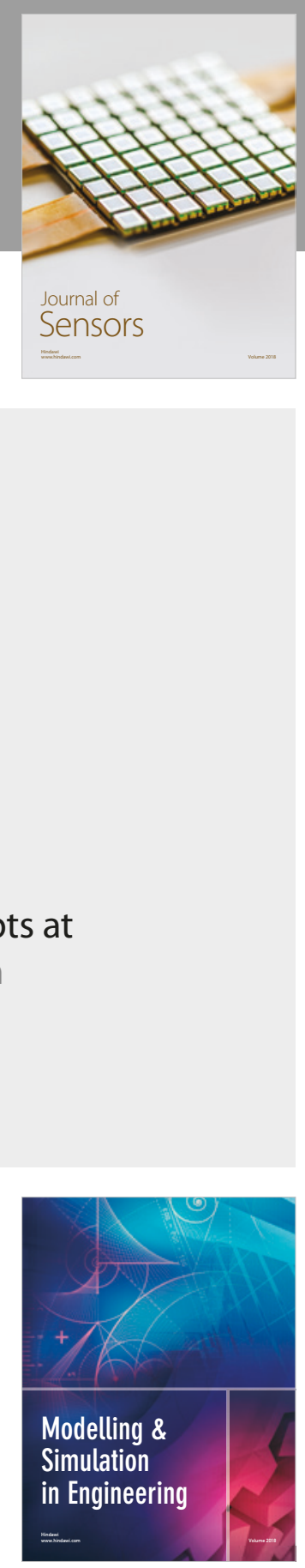

\section{Advances \\ Multimedia}
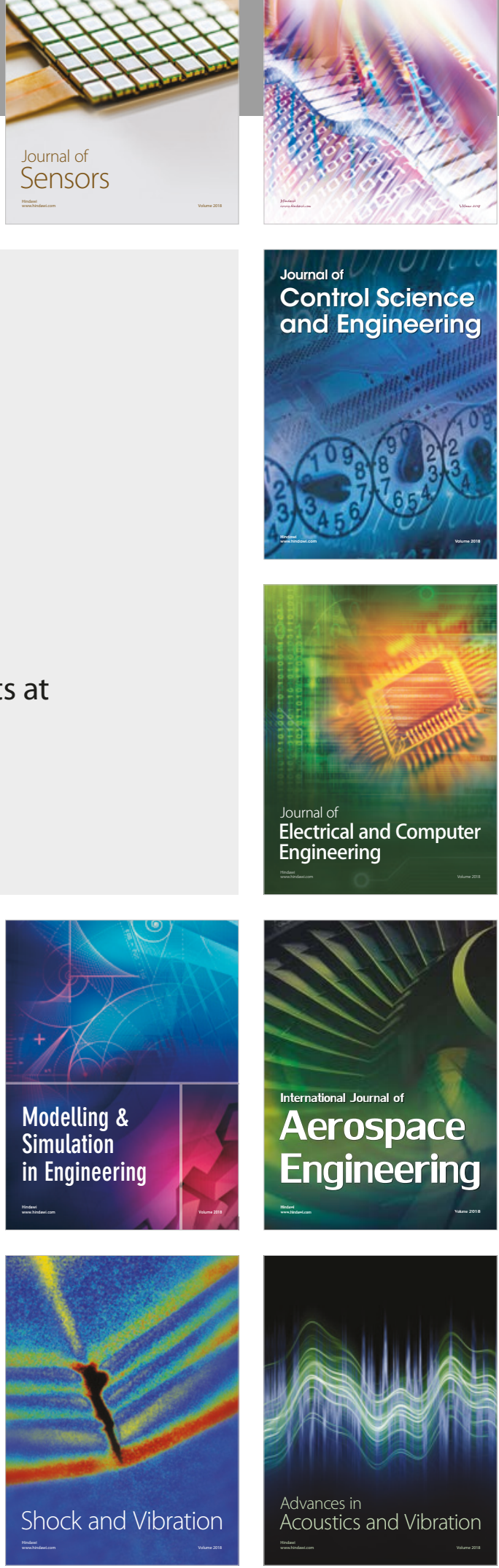